\title{
AVALIAÇÃO DO ÍNDICE DE SOROPROTEÍNA NÃO- DESNATURADA COMO UM INDICADOR DE TRATAMENTO TÉRMICO PARA LEITE UHT E LEITE EM PÓ
}

\section{Assessment of whey protein nitrogen index as an indicator of heat treatment for UHT milk and milk powder}

\author{
Leandra Natália Oliveira ${ }^{*}$, Vanessa Toledo Marinho ${ }^{I}$, Marilana Vidal Zamagno ${ }^{I}$, \\ Maraíse Aparecida Lauro ${ }^{\prime}$, Jéssica Aparecida Norvino Barboza ${ }^{l}$, \\ Paulo Henrique Fonseca da Silval
}

\begin{abstract}
RESUMO
Durante o processamento térmico de produtos lácteos ocorrem diversas modificações químicas dentre as quais a desnaturação de soroproteínas é bastante evidente e estudada. Este fenômeno pode gerar gelificação em leite UHT e problemas de solubilização em leite em pó, dois importantes produtos lácteos amplamente difundidos no mercado nacional. O índice de soroproteína não-desnaturada (WPNI) pode ser uma ferramenta útil para avaliar o grau de severidade ao qual o leite está sendo submetido e, portanto, permite inferir sobre a ocorrência dos possíveis defeitos associados à desnaturação proteica. Neste estudo, verificou-se o teor de soroproteína não-desnaturada como indicador de tratamento térmico em leite submetido aos processamentos de ultrapasteurização e de secagem. As amostras comerciais de leite UHT e leite em pó analisadas apresentaram um intervalo de confiança de WPNI $(2,39 \pm 1,41) \mathrm{mg} \mathrm{WPN} . \mathrm{mL}^{-1}$ e $(2,63 \pm 1,38) \mathrm{mg}$ WPN.mL $\mathrm{m}^{-1}$, respectivamente. De acordo com a análise estatística de variância, todas as amostras avaliadas diferiram entre si com um p-valor $<0,001$; sendo que $90 \%$ das amostras de leite UHT e $67 \%$ para as amostras de leite em pó foram classificadas como submetidas a médio tratamento térmico. Os dados obtidos permitiram inferir sobre a severidade do tratamento térmico associado a cada tipo de produto analisado e foram capazes de demonstrar a falta de padronização dos processos de tratamento térmico nas amostras estudadas, fato este que pode ter como consequência o desenvolvimento de características indesejáveis nos produtos ao longo do período de estocagem e comercialização.
\end{abstract}

Palavras-chave: desnaturação; processamento térmico; qualidade; desidratação.

1 Universidade Federal de Juiz de Fora, Departamento de Química, Rua José Lourenço Kelmer, s/n, Campus Universitário, São Pedro, 36036-900, Juiz de Fora, MG, Brasil. E-mail: leandra.oliveira@ufjf.edu.br

* Autor para correspondência.

Recebido / Received: 15/12/2014

Aprovado / Approved: 15/06/2015

Rev. Inst. Laticínios Cândido Tostes, Juiz de Fora, v. 70, n. 2, p. 78-84, mar/abr, 2015 


\begin{abstract}
During heat treatment of dairy products it is possible to occur several chemical modifications which whey protein denaturation is quite evident and studied. This phenomenon can cause gelation in UHT milk and some problems in reconstitution of milk powder, two major dairy products widely used in dairy foods and by consumer. The whey protein nitrogen index (WPNI) can be an useful tool to assess the degree of severity that milk was submitted, and therefore inferred from the occurrence of possible defects associated with protein denaturation. This study presents the evaluation of the non-denaturated whey protein contents as a heat treatment indicator for ultrapasteurization and drying milk processing. Commercial samples of UHT milk and milk powdershowed WPNI confidence interval of $(2.39 \pm 1.41) \mathrm{mgWPN}_{\mathrm{m}} \mathrm{mL}^{-1}$ and $(2.63 \pm 1.38) \mathrm{mgWPN} . \mathrm{mL}^{-1}$, respectively. According to the statistical analysis of variance, all samples differed with a p-value $<0.001$; and $90 \%$ of UHT milk and $67 \%$ milk powder samples were classified as medium heat treatment. It was possible to infer the severity of the heat treatment associated with each kind of product analyzed. The results were able to demonstrate the lack of standardization of heat treatment processes on the samples studied, a fact that may result in the growth of undesirable characteristics in the products during the storage or commercialization.
\end{abstract}

Keywords: denaturation; heat processing; quality; drying.

\section{INTRODUÇÃO}

Processos industriais como tratamento térmico, concentração e secagem do leite são aplicados e aprimorados pelas indústrias a fim de se reduzir custos com transporte, armazenamento, aumentar o período de vida útil dos produtos, minimizar impactos ambientais e, consequentemente, ampliar o mercado de exportação.

O leite em pó ocupa lugar de destaque na cadeia leiteira produtiva, visto sua grande aplicabilidade dietética e potencial de comércio, requerendo constantes inovações nas tecnologias e no controle de qualidade.

Desde 1972 o leite Longa Vida, como também é conhecido o leite UHT, tem-se mantido como vetor de crescimento do mercado de leite fluido no Brasil. Atualmente, o produto está presente em $86 \%$ dos lares brasileiros e representa $76 \%$ do volume de leite fluido consumido. Com grande representatividade para a cadeia láctea, equivale, ainda, a aproximadamente $30 \%$ do destino do leite inspecionado captado no País (MILKPOINT, 2014).

O tratamento térmico de produtos lácteos apresenta como finalidade a manutenção dos aspectos de saúde pública, promovendo eliminação de patógenos e a conservação do alimento, por meio da inativação de enzimas e microrganismos deteriorantes. No entanto, a aplicação do calor provoca alterações químicas reversíveis e irreversíveis que afetam diretamente o produto final.

Durante o processo de ultrapasteurização, o leite é submetido a elevadas temperaturas por curtos períodos de tempo. Segundo Walstra; Jenness (1984), as principais modificações causadas pela aplicação do calor ao leite são: eliminação de gases; aumento na quantidade de fosfato coloidal e diminuição da concentração de cálcio iônico, isomerização da lactose, que sofre uma degradação parcial, formando lactulose e ácidos orgânicos; hidrólise dos ésteres fosfóricos, particularmente os da 
caseína; diminuição do $\mathrm{pH}$ do leite e aumento do valor de sua acidez; insolubilização de grande parte das soroproteínas devido à desnaturação; inativação de enzimas; reação entre as proteínas e a lactose, especialmente a reação de Maillard, tendo como consequência à diminuição da lisina disponível; formação de grupos sulfidrila livres e agregação das micelas de caseína.

Fenômenos de desnaturação e agregação de soroproteínas e sua interação com caseínas durante o processamento térmico desempenham um importante papel nas propriedades funcionais do produto final (PATEL et al., 2007). O efeito destes fenômenos no leite em pó, assim como no leite UHT, depende da intensidade e do tempo do tratamento térmico aplicado. O leite em pó desnatado pode ser classificado quanto ao tipo de tratamento térmico em que é submetido de acordo com as especificações do American Dairy Products Institute (ADPI), apresentadas na Tabela 1 (PATEL et al., 2007; PERRONE et al., 2008).

O grau de desnaturação de soroproteínas em leites tratados termicamente é usualmente indicado pelo índice de nitrogênio de soroproteína não-desnaturada (whey protein nitrogen index - WPNI) o qual é mensurado a partir do teor (em miligramas) de nitrogênio de soroproteínas não-desnaturadas (undenaturated whey protein nitrogen - WPN) por miligrama de pó ou mililitro de leite fluido (PATEL et al., 2007). Neste contexto, a fração proteica do soro de leite é frequentemente utilizada como um indicador para monitoramento dos efeitos do calor sob os produtos lácteos, uma vez que tais proteínas são diretamente afetadas.

Para produtos submetidos a médio tratamento térmico, a agregação proteica é caracterizada por interações entre as soroproteínas via grupos sulfidrilas, enquanto que, em produtos de alto tratamento térmico a agregação proteica resulta principalmente pela ocorrência de interações entre $\beta$-lactoglobulinas e $\kappa$-caseínas por meio de ligações dissulfídicas (ROBINSON, 1986). Tais interações aumentam o grau de hidrofobicidade do produto e podem interferir diretamente nas propriedades funcionais do mesmo.

Para leite em pó, a instantaneidade pode ser definida como a capacidade que o produto apresenta em se dissolver por completo em poucos segundos. A reconstituição do produto depende de propriedades funcionais intrínsecas da partícula do pó, adquiridas ao longo do processamento e totalmente dependente deste. Tais propriedades são definidas como molhabilidade, penetrabilidade, dispersabilidade e solubilidade (PERRONE et al., 2008) e definem a aplicabilidade do produto final, como leite em pó para consumo direto e leite em pó para formulações dietéticas como fabricação de sorvetes, chocolates, pães dentre outras (PATEL et al., 2007).

A falta de padronização dos produtos em relação às suas funcionalidades e

Tabela 1 - Classificação de leite tratado termicamente de acordo com o tipo de tratamento térmico (adaptado de PATEL et al., 2007; PERRONE et al., 2008)

\begin{tabular}{ccc}
\hline Classificação do produto & WPNI (mg WPN.mL-1 leite) & Tratamento térmico \\
\hline Baixo tratamento & $\geq 6,0$ & $75^{\circ} \mathrm{C} / 20 \mathrm{~s}$ \\
Médio tratamento & $1,51-5,99$ & $85^{\circ} \mathrm{C}-105^{\circ} \mathrm{C} / 1$ min. $-2 \mathrm{~min}$. \\
Alto tratamento & $<1,50$ & $120^{\circ} \mathrm{C}-135^{\circ} \mathrm{C} / 2 \mathrm{~min} .-3 \mathrm{~min}$. \\
Alto tratamento - & $<1,50$ & $125^{\circ} \mathrm{C}-135^{\circ} \mathrm{C} / 2 \mathrm{~min} .-6 \mathrm{~min}$. \\
\hline
\end{tabular}


aplicabilidades pode ser reduzida por modificações e adequações dos processos tecnológicos visando melhorar as características físicas e nutricionais dos mesmos. Neste sentido, a avaliação dos indicadores de tratamento térmico torna-se fundamental para diagnosticar o perfil do produto comercializado.

Este estudo teve como objetivo estimar o índice de nitrogênio de soroproteína nãodesnaturada (WPNI) em amostras comerciais de leite em pó integral e leite UHT desnatado a fim de se obter informações acerca da severidade do tratamento térmico a que foram submetidas, permitindo inferir sobre seus aspectos nutricionais.

\section{MATERIAL E MÉTODOS}

Vinte e sete amostras de nove marcas comerciais de leite em pó integral, correspondentes a três lotes diferentes e sessenta amostras de vinte marcas de leite UHT desnatado, também oriundas de três lotes diferentes, foram coletadas e analisadas em triplicata quanto ao teor de WPNI, por método turbidimétrico (KURAMOTO et al., 1959).

As amostras de leite em pó foram reconstituídas a $10 \% \mathrm{~m} / \mathrm{v}$ de sólidos lácteos não gordurosos, sendo as amostras de leite desnatado UHT isentas desta etapa. Procedeuse à precipitação da caseína por "salting out" empregando $10 \mathrm{~mL}$ de amostra reconstituída e $4 \mathrm{~g}$ de cloreto de sódio p.a., mantendo o sistema em banho termostático a $37^{\circ} \mathrm{C}$ durante trinta minutos. Após filtração do sistema, procedeu-se a acidificação de $1 \mathrm{~mL}$ do filtrado com duas gotas de solução de ácido clorídrico
$10 \% \mathrm{v} / \mathrm{v}$, em solução supersaturada de cloreto de sódio para produção de turbidez. A leitura da transmitância a $420 \mathrm{~nm}$ foi realizada em espectrofotômetro UV/Visível Thermo Scientific modelo Evolution 60S. O resultado de WPNI, expresso em miligrama de WPN por $\mathrm{mL}$ de produto, deu-se a partir da construção de uma curva analítica (transmitância vs. WPNI), com faixa de detecção de $0,63 \mathrm{mg} \cdot \mathrm{g}^{-1}$ a 7,86 mg. $\mathrm{g}^{-1}$. A curva analítica foi obtida por intermédio da combinação de padrões de leite em pó submetido a alto aquecimento (baixa concentração de WPN) e leite submetido a baixo aquecimento (elevada concentração de WPN) versus transmitância, de acordo com ADPI (2009).

Para a análise estatística descritiva e análise de variância (ANOVA) dos dados obtidos foi utilizado o software Prisma 5.0 (GraphPad, CA, USA).

\section{RESULTADOS E DISCUSSÃO}

A análise estatística descritiva referente ao teor de WPNI para as amostras de leite em pó e leite UHT analisadas está disposta na Tabela 2 .

A média do teor de WPNI para ambos os produtos analisados mostrou-se bastante semelhante apesar de serem produtos submetidos a diferentes tratamentos térmicos. Como o processamento de leite em pó utiliza equipamentos a vácuo para a concentração prévia, a temperatura em que o produto é submetido tende a ser reduzida, fato este que pode corroborar para um maior teor de WPNI.

Tabela 2 - Análise estatística descritiva do teor de WPNI das amostras de leite em pó $(\mathrm{n}=27)$ e leite UHT $(n=60)$

\begin{tabular}{lcc}
\hline \multicolumn{1}{c}{ Parâmetro } & Leite UHT & Leite em Pó \\
\hline Intervalo de Confiança (mg WPN. $\mathrm{mL}^{-1}$ leite) & $2,39 \pm 1,41$ & $2,63 \pm 1,38$ \\
Amplitude (mg WPN. mL ${ }^{-1}$ leite) & 4,91 & 6,35 \\
Coeficiente de variação (\%) & 49,4 & 69,7 \\
\hline
\end{tabular}


Verificou-se amplitude mais elevada para o teor de WPNI em leite em pó, o que permite inferir sobre a ocorrência de falta de uniformidade do produto comercializado. Esta falta de padronização torna-se um fator desfavorável ao consumidor, o qual pode encontrar alterações no consumo direto do produto ou dificuldades em seu uso, devido às consequentes modificações em suas propriedades funcionais como molhabilidade, penetrabilidade, dispersabilidade e solubilidade (PERRONE et al., 2008). Além disso, modificações no valor nutricional do produto podem ocorrer devido às modificações conformacionais das soroproteínas e perdas de aminoácidos como a lisina (VAN BOEKEL, 1998).

De acordo com Browning et al. (2001) e Elliott et al. (2005), períodos de aquecimento e resfriamento prolongados durante o tratamento térmico podem resultar em produtos similares àqueles submetidos ao processo de esterilização, visto os efeitos químicos e biológicos agregados durante estas duas etapas. Portanto, é de se esperar que danos provocados pelo calor durante o tratamento UHT sejam mais intensos em sistemas indiretos, quando comparado a sistemas diretos; uma vez que o dano causado depende do tempo de exposição do produto ao calor (MORTIER et al., 2000). Neste caso, variações no tipo de processamento UHT tende a gerar variações no teor de soroproteína desnaturada, visto que este fenômeno é dependente do tempo de exposição ao calor. Os resultados apresentados na Tabela 2 evidenciaram variação de, aproximadamente,
37 pontos percentuais no teor de WPNI das amostras de leite UHT analisadas, podendo esta variação estar associada ao emprego de diferentes tipos de troca de calor (indireto e direto) durante o processamento UHT, além de possíveis modificações das variáveis tempo/temperatura facilmente modificadas pela indústria.

A Tabela 3 mostra a análise de variância aplicada entre todas as amostras e entre os diferentes tratamentos térmicos avaliados (secagem e esterilização comercial). Pode-se observar variações significativas no teor de WPNI mesmo quando se avalia o mesmo tipo de processamento térmico, sugerindo a existência de falta de padronização de ambos tratamentos térmicos avaliados. Pode-se verificar ainda a classificação das amostras de acordo com a severidade do tratamento térmico aplicado.

A maioria das amostras de leite em pó e leite UHT se enquadrou na classificação de médio tratamento térmico. No entanto, nenhuma amostra de leite UHT e apenas $11 \%$ das amostras de leite em pó analisadas foram classificadas como baixo tratamento térmico (PATEL et al.,2007; PERRONE et al., 2008).

Para o processamento UHT o controle da exposição do produto ao calor é de grande importância para a manutenção não somente das características nutricionais do produto, mas também de suas funcionalidades. Silva (2004) verificou correlação positiva entre a taxa de sedimentação ao longo da estocagem do leite UHT e o nível de desnaturação proteica no produto.

Tabela 3 - Análise de variância do teor de WPNI entre leite em pó $(\mathrm{n}=27)$ e leite UHT $(\mathrm{n}=60)$ e classificação de acordo com o tratamento térmico

\begin{tabular}{ccccc}
\hline Produtos & ANOVA & $\begin{array}{c}\text { Baixo } \\
\text { aquecimento }\end{array}$ & $\begin{array}{c}\text { Médio } \\
\text { aquecimento }\end{array}$ & $\begin{array}{c}\text { Alto } \\
\text { aquecimento }\end{array}$ \\
\hline Todas as amostras & $\mathrm{p}<0,001$ & $3,5 \%$ & $82,7 \%$ & $13,8 \%$ \\
Leite UHT & $\mathrm{p}<0,001$ & ---- & $90,0 \%$ & $10,0 \%$ \\
Leite em pó & $\mathrm{p}<0,001$ & $11,1 \%$ & $66,6 \%$ & $22,2 \%$ \\
\hline
\end{tabular}


Estudos apontam que o efeito acumulativo das diversas etapas de aquecimento ao longo do processamento bem como variações nos parâmetros como fluxo do produto no equipamento ou eventual recirculação tendem a interferir no nível de desnaturação proteica (SILVA, 2004).

A desnaturação das soroproteínas é caracterizada pela agregação das moléculas, portanto, quanto mais severo o tratamento térmico maior o nível de agregação, fato este que pode intensificar a formação de sedimentos no produto final (RENNER; SCHMIDT, 1981). A ocorrência de sedimentos durante a estocagem do leite UHT é considerada um dos maiores problemas para as indústrias que o processam, uma vez que geram a necessidade de interrupções com maior frequência para limpeza de equipamentos e tubulações além de reduzir a vida de prateleira e ocasionar rejeição do produto pelo consumidor.

Para o leite em pó, de acordo com Patel et al. (2007), conforme o grau de desnaturação de soroproteína o produto tende a exibir propriedades funcionais diferentes pós-processamento e ao longo do período de estocagem. De acordo com Yazdanpanah e Langrish (2013) a partícula de leite em pó com elevados teores de desnaturação proteica tende a apresentar maior tendência à cristalização da lactose durante o período de estocagem, fato este que pode influenciar negativamente o processo de reconstituição do produto ou sua aplicação em outros alimentos. Murrieta-Pazos et al.(2011) sugere que a perda das funcionalidades do leite em pó tende a ser mais intensa quando o produto apresenta baixos teores de lipídios, visto a maior concentração de lactose e proteínas desnaturadas na superfície da partícula do pó.

Verifica-se desta forma, uma ocorrência de variações significativas no teor de WPNI para um mesmo tipo de processamento térmico e entre diferentes produtos, fato este que pode estar associado à falta de padronização das variáveis tempo e temperatura empregadas.
Do ponto de vista nutricional, deseja-se que o tratamento térmico aplicado ao leite seja o menos severo possível, visto ser potencialmente capaz de ocasionar perdas de vitaminas, reação de escurecimento nãoenzimático, interações e oxidações de nutrientes, alterações conformacionais nas proteínas e bloqueio de aminoácidos indispensáveis, como a lisina (DESROSIER, 1995; TOMÉ, 1995).

\section{CONCLUSÕES}

Os resultados do presente estudo sugerem que os tratamentos térmicos devem ser monitorizados quanto às modificações químicas, uma vez que estes apresentam particularidades e variações, tais como a temperatura e tempo de exposição. A metodologia utilizada é facilmente capaz de inferir sobre a severidade do tratamento térmico adotado e permite avaliar e classificar os produtos em termos de exposição prolongada ao calor.

De acordo com os dados coletados, esforços devem ser realizados para alcançar maior proporção de amostras de ambos os processamentos avaliados classificadas como baixo tratamento térmico visto que nesta classe espera-se a baixa ocorrência de modificações químicas e nutricionais. Também deve-se otimizar o processamento e reduzir custos, principalmente quanto ao processamento UHT o qual não apresentou marcas se enquandrando na classificação baixo tratamento térmico.

\section{AGRADECIMENTOS}

Os autores agradecem à FAPEMIG e à GEMACOM Tech pelo apoio.

\section{REFERÊNCIAS}

AMERICAN DAIRY PRODUCTS INSTITUTE (ADPI). Standards for grades of 
dry milks. $3^{\text {th }}$ Edition. Bulletin 916. New York: ADPI, 2009. 45p.

BRASIL. Ministério de Estado da Agricultura, Pecuária e Abastecimento. Portaria n ${ }^{\circ} 370$, de 4 de setembro de 1997. Regulamento técnico para fixação de identidade e qualidade do leite UHT (UAT). Diário Oficial da República Federativa do Brasil, Brasília, 8 set. 1997. Seção 1, p. 19700.

B R O W N I N G, E .; L E W I S , M .; MACDOUGALL, D. Predicting safety and quality parameters for UHT-processed milks. International Journal of Dairy Technology, v. 54, n. 3, p. 111-120, 2001.

DESROSIER, T. Technological treatment of infant formula: processing and mineral changes. International Dairy Federation Nutrition Newsletter, n. 143, p. 10-13, oct. 1995.

ELLIOTT, A. J. et al. Heat-induced and other chemical changes in commercial UHT milks. Journal of Dairy Research, v. 72, n. 4, p. 442-446, 2005.

KURAMOTO, S. et al. Standardization of the Harland-Ashworth test for whey protein nitrogen. Journal of Dairy Science, v. 42, n. 1, p. 28-38, 1959.

MILKPOINT Queda nas importações brasileiras de leite em pó em 2013. Disponível em: <http://www.scotconsultoria.com.br/ leite/balanca-comercial/354/queda-nasimportacoes-brasileiras-de-leite-em-poem-2013.htm> Acesso em: 02 ago. de 2014.

MORTIER, L. et al. Intrinsic indicators for monitoring heat damage of consumption milk. Biotechnology, Agronomy, Society and Environment, v. 4, n. 4, p. 221-225, 2000.

MURRIETA-PAZOS, I. et al. Comparative study of particle structure evolution during water sorption: Skim and whole milk powders Colloids and Surfaces B: Biointerfaces, v. 87, n. 1, p. 1-10, 2011.

PATEL, H. A. et al. Methods to determine denaturation and aggregation of proteins in low-, medium- and high-heat skim milk powders. Lait, v. 87, n. 4-5, p. 251-268, 2007.

PERRONE, I. T., OLIVEIRA, L. N.; FARIA, L. M. G. C. Aspectos tecnológicos da produção do leite em pó instantâneo. Revista do Instituto de Laticínios Cândido Tostes, v. 361, n. 63, p. $35-37,2008$.

RENNER, E.; SCHMIDT, R. H. Chemical and physic-chemical aspects. In: International Dairy Federation. New monograph on UHT milk. Brussels, p. 49-64. 1981. (Document, 133).

ROBINSON, R. K. Modern Dairy Techonology - Advances in Milk Processing. New York: Elsevier Applied Science, 1986. 438p.

SILVA, P. H. F. Leite UHT: Fatores determinantes para sedimentação e gelificação. 1ª Edição. Juiz de Fora: Templo, 124 p. 2004.

TOMÉ, D. Influence of processing on the nutritional value of milk proteins. International Dairy Federation Nutrition Newsletter, n. 143 , p. $08-10$, oct. 1995 .

VAN BOEKEL, M. A. J. S. Effect of heating on Maillard reactions in milk. Food Chemistry, v. 62, n. 4 , p. 403-414, 1998.

WALSTRA, P.; JENNESS, R. Química y física lactológica. Zaragoza: Acribia, 1984. $423 \mathrm{p}$.

YAZDANPANAH, N.; LANGRISH, T. A. G. Comparative study of deteriorative changes in the ageing of milk powder. Journal of Food Engineering, v. 114, n. 1, p. 14-21, 2013. 